\title{
Endoscopic removal of a proximally migrated pancreatic stent
}

A 64-year-old woman with choledocholithiasis underwent endoscopic retrograde cholangiopancreatography (ERCP) with stone extraction and biliary and pancreatic duct (PD) stent placement. She subsequently presented with postprandial abdominal distension of a few weeks' duration. The patient had undergone a laparoscopic cholecystectomy following the ERCP; however, a repeat ERCP nearly 2 months after her initial endoscopy revealed a proximally migrated PD stent that could not be retrieved, prompting transfer to our center.

Repeat ERCP revealed a normal-appearing PD with a retained PD stent, which had migrated towards the pancreas. The ventral PD was deeply cannulated with a short-nosed traction autotome, and a pancreatic sphincterotomy was performed. A pediatric biopsy forceps was then advanced into the duct over the wire, and closed over the pancreatic stent, but the stent appeared to be embedded. Further attempts to extract the PD stent with a rat tooth forceps and retrieval basket were also unsuccessful. The PD was then dilated with a 4-mm hurricane balloon and the pediatric biopsy forceps was again advanced over the wire, with successful extraction and complete removal of the retained $\mathrm{PD}$ stent ( Fig.1, Video1). One $5 \mathrm{Fr} \times 12 \mathrm{~cm}$, single-pigtail, plastic stent was placed into the ventral PD to prevent post-ERCP pancreatitis. The patient was discharged home the same day. At post-ERCP followup, the patient remained pain free and had normal liver chemistry.

The removal of proximally migrated PD stents remains technically challenging owing to the small diameter, bending course, and often stricturing of the PD. Many devices have been successfully used for endoscopic removal of migrated stents, including a basket, snare, extraction balloon, and grasping forceps. Despite the lack of a standardized approach to migrated pancreatic stents, ERCP
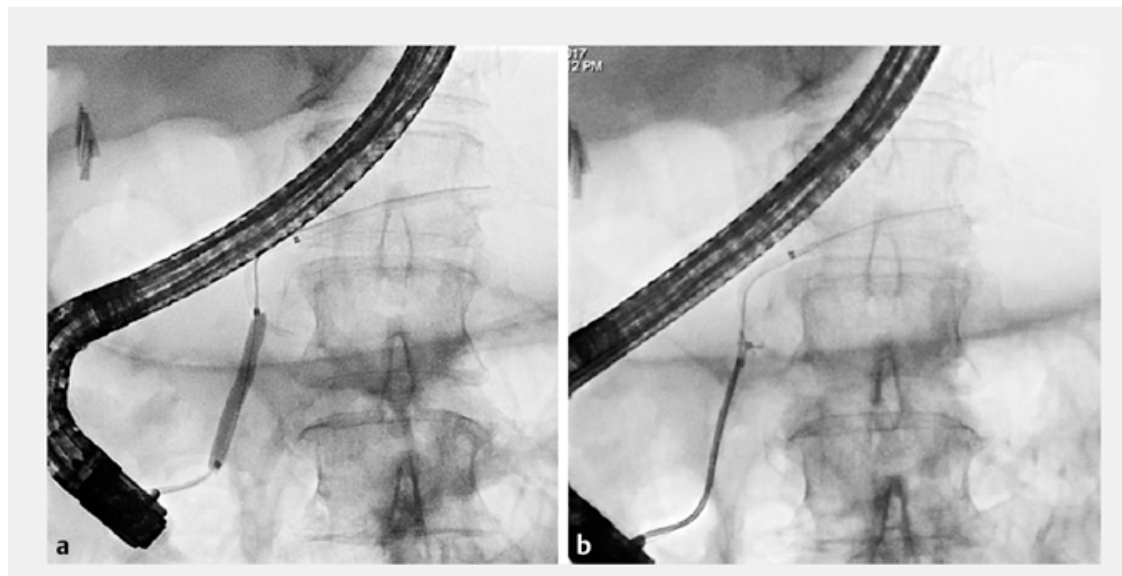

- Fig. 1 Endoscopic retrograde cholangiopancreatography. a Unintentional proximal migration of a pancreatic duct (PD) stent in a 64-year-old female patient. Here, the PD is being dilated with a 4-mm hurricane balloon. $\mathbf{b}$ A pediatric biopsy forceps is seen grasping the migrated PD stent, with successful retrieval.
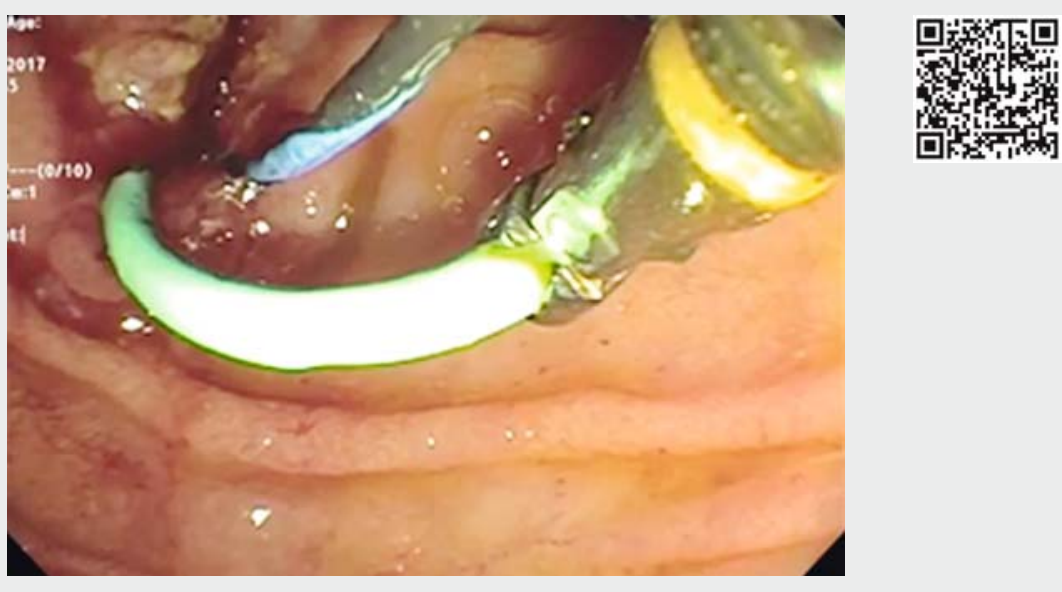

$\nabla$ Video 1 Extraction of an imbedded pancreatic duct stent with a pediatric biopsy forceps after balloon dilation.

should be attempted at an experienced center for retrieval of a proximally migrated PD stent prior to considering surgical intervention [1].

Endoscopy_UCTN_Code_TTT_1AR_2AZ

\section{Competing interests}

Dr. Kahaleh has received grant support from Boston Scientific, Fujinon, EMcison, Xlumena Inc., W.L. Gore, MaunaKea, Apollo Endosurgery, Cook Endoscopy, ASPIRE Bariatrics, GI Dynamics, NinePoint Medical, Merit Medical, Olympus and MI Tech. He is a consultant for Boston Scientific, Xlumena Inc., Concordia Laboratories Inc, ABBvie, and MaunaKea Tech. 
The authors

Shawn L. Shah, Enad Dawod, Michel Kahaleh Division of Gastroenterology and Hepatology, New York-Presbyterian/Weill Cornell Medical Center, New York, New York, United States

\section{Corresponding author}

\section{Michel Kahaleh, MD}

Division of Gastroenterology and

Hepatology, Weill Cornell Medical, 1305 York Avenue, 4th Floor, New York, NY 10021,

United States

Fax: +1-646-962-0110

mkahaleh@gmail.com
[1] Matsumoto K, Katanuma A, Maguchi H. Endoscopic removal technique of migrated pancreatic plastic stents. J Hepatobiliary Pancreat Sci 2014; 21: E34-E40

\section{Bibliography}

DOI https://doi.org/10.1055/s-0043-123875

Published online: 2.2.2018

Endoscopy 2018; 50: E90-E91

(c) Georg Thieme Verlag KG

Stuttgart · New York

ISSN 0013-726X
ENDOSCOPY E-VIDEOS

https:/|eref.thieme.de/e-videos

口回 Endoscopy E-Videos is a free 然故 access online section, reporting 回舴: on interesting cases and new techniques in gastroenterological endoscopy. All papers include a high quality video and all contributions are freely accessible online.

This section has its own submission website at

https://mc.manuscriptcentral.com/e-videos 